\title{
APPLICATION OF ARTIFICIAL INTELLIGENCE METHODS IN DRILLING SYSTEM DESIGN AND OPERATIONS: A REVIEW OF THE STATE OF THE ART
}

\author{
Opeyemi Bello ${ }^{1}$, Javier Holzmann ${ }^{1}$, Tanveer Yaqoob $^{1}$, Catalin Teodoriu ${ }^{2}$ \\ ${ }^{1}$ Institute of Petroleum Engineering, Clausthal University of Technology, Germany \\ e-mail: oob@tu-clausthal.de \\ ${ }^{2}$ Mewbourne School of Petroleum and Geological Engineering, University of Oklahoma
}

\begin{abstract}
Artificial Intelligence (AI) can be defined as the application of science and engineering with the intent of intelligent machine composition. It involves using tool based on intelligent behavior of humans in solving complex issues, designed in a way to make computers execute tasks that were earlier thought of human intelligence involvement. In comparison to other computational automations, AI facilitates and enables time reduction based on personnel needs and most importantly, the operational expenses.

Artificial Intelligence (AI) is an area of great interest and significance in petroleum exploration and production. Over the years, it has made an impact in the industry, and the application has continued to grow within the oil and gas industry. The application in E \& P industry has more than 16 years of history with first application dated 1989, for well $\log$ interpretation; drill bit diagnosis using neural networks and intelligent reservoir simulator interface. It has been propounded in solving many problems in the oil and gas industry which includes, seismic pattern recognition, reservoir characterisation, permeability and porosity prediction, prediction of PVT properties, drill bits diagnosis, estimating pressure drop in pipes and wells, optimization of well production, well performance, portfolio management and general decision making operations and many more.

This paper reviews and analyzes the successful application of artificial intelligence techniques as related to one of the major aspects of the oil and gas industry, drilling capturing the level of application and trend in the industry. A summary of various papers and reports associated with artificial intelligence applications and it limitations will be highlighted. This analysis is expected to contribute to further development of this technique and also determine the neglected areas in the field.
\end{abstract}

\section{Introduction}

Artificial Intelligence, otherwise known as machine learning or computational intelligence is the science and engineering in creating intelligent machines. It has been applied in solving complex practical related complications in various field applications becoming more popular and acceptable.
AI techniques characteristic include ability to learn from examples; fault tolerant managing noisy and deficient data; ability to deal with non-linear problems; and for prediction purpose and generalization at high speed once trained. AI techniques are developed and deployed worldwide in a myriad of applications as a result of its symbolic reasoning, explanation capabilities potential and flex- 
ibility. According to Shahab (2011), the technology had the ability to learn and deal with a new situations by processing one or more attributes of reason that facilitate solving problems which were previously difficult or impossible to solve. Most of the artificial intelligence techniques or tools have shown tremendous potential for generating accurate analysis and results from large historical databases, the kind of data an individual or engineers may not consider valuable in conventional modelling and analysis processes (Shahab 2000).

AI has been used in many areas of applications in solving classification, diagnosis, selection and prediction problems. The techniques models capture the uncertainty between real-life cause and effect scenarios hence incorporating available episteme with probabilities and probability inference computations. (Jianhong et al., 2003; Patterson 1990).

The most widely used techniques include artificial neural networks, fuzzy logic, expert systems, and generic algorithms with interesting developments in hybrid. Other existing techniques include support vector machines, functional network, cased based reasonining and expert systems. Most of the artificial intelligence techniques have shown great potential in generating accurate analysis and results in different area of applications such as engineering, banking, medicine, economics, military, marine, etc. They have also been applied for identification, selection, optimization, prediction, forecasting, and control of complex systems (Mellit et.al, 2008).

In recent years, there has been a rapid increase in the number of artificial intelligence tools applications in petroleum industry due to greater availability of human expert and numerous publications of successful application case studies (Gharbi et. al. 2005). Artificial neural networks, fuzzy logic and evolutionary algorithms are the most commonly used AI techniques today in various petroleum engineering applications; oil and gas reservoir simulation, production, drilling and completion optimization, drilling automation and process control (Braswell 2013).

With the recent successful result of AI as intelligent systems tools in E \& $\mathrm{P}$ industry, it is becoming explicit that our industry has realized the importance applicability of the intelligent model solv- ing several disciplinary related problems. There is a great potential for these tools in exploration, production and management of hydrocarbons.

Drilling operation activities on artificial intelligence have evolved over the years giving flexibility in selection, monitoring, diagnosing, predicting, and optimizing, thus impact in overall efficiency and profitability cannot be overemphasized.

This paper identifies and analyzes the improvement potential of artificial intelligence techniques as applied to drilling system design and operations. Additionally, limitations on each one of the artificial intelligence are also summarized.

\section{Literature Review}

\subsection{AI Techniques}

Artificial intelligence (AI) is a branch of computer science that in its broadest sense would mean the ability of a machine to perform or in an attempt to mimic the operations of human brains or human thought, understand and apply thinking methodologies (Kalogirou, 2003). It is an approach of solving engineering difficulties with the ability to consider all effective parameters simultaneously. The central principles of AI include reasoning, knowledge, planning, learning, communication, perception and the ability manipulate objects (Bhattacharyya, 2011). Furthermore, it has generalization and potential learning directly from field data.

Currently, AI algorithms have drawn the attention of researchers and applied successfully solving problems at different area of fields and that is why much relevant research has been conducted. This includes medical system, educational field, oil and gas industry, telecommunications, law, remote sensing, scientific discovery and gaming. Other applications include; banking sector, petrochemical industry, and military activity controls, nuclear management, shipping industry, public sector (employee performance evaluation) and many more. According to Artificial Intelligence Applications Institute (AIAI), AI technologies transfer's areas of application are as follows:

- case-based reasoning: a methodology adaptation based on past evidences and existing cor- 
porate resources such as databases to pilot diagnosis and fault finding;

- genetic algorithms: a search technique adaption with very broad applicability in scheduling, optimization, and model adaptation;

- planning and workflow: the modelling, task setting, planning, execution, monitoring and coordination of different endeavours;

- intelligent systems: an approach of building knowledge-based systems.

\subsection{Benefits and Limitations of AI Tech- niques}

\subsubsection{Benefits of Artificial Intelligence Tech- niques}

The main goal of seeking smart machine methods is to predict the occurrence of some problems based on previous experience with reasonable cost and time. The reliability of the method depends on the accuracy of prediction and the error between the actual and the predicted class labels of the problem. According to Kecman (2001), many scientific and engineering fields have recently applied artificial intelligence to predict common and serious problems. They seek AI methods due to the complications of most today problems which are hard to be solved through the traditional methods or what is called hard computing.

The benefits of AI techniques are highlighted as follows (after Mellit 2008; Medsker 1996; Medsker 1996; Tu 1996. and Benghanem 2012):

i. The leverage AI techniques has over other modelling techniques is their ability to model complex, non-linear processes without any form of relationship assumption between input and output variables.

ii. As a developing and promising technology, AI has become extremely popular for prediction, diagnosis, monitoring, selection, forecasting, Inspection and identification in different fields.

iii. AI are more accurate than other models and empirical models for predictions using linear or non-linear multiple regression or graphical techniques. iv. AI has a great potential for generating accurate analysis and results from large historical databases. The kind of data that most engineers may not consider valuable or relevant in conventional modelling and analysis processes.

v. AI tools have the ability to analyze large quantities of data to establish patterns and characteristics in situations where rules are not known and sometimes in many cases make sense of incomplete or noisy data

vi. AI tools are cost effective. ANN as example has the advantage of execution speed, once the network has been trained. The ability to train the system with data sets, rather than having to write programs, may be more cost effective and may be more convenient when changes become vital.

vii. AI tools can implicitly detect complex nonlinear relationships between independent and dependent variables.

viii. AI tools can be developed using multiple different training algorithms

ix. Tackle boring tasks and can complete task faster than a human with less errors and defects

\subsubsection{Limitations of Artificial Intelligence Techniques}

Like any other tool, AI techniques have their own limitations. An example is ANN which is often tagged as black boxes that merely attempt to map a relationship between output and input variables based on a training data set. This raises some concerns regarding the ability of the tool to generalize to situations that were not well represented in the data set (Lint et al., 2002). However one proposed solution in addressing the black box problem is the combination of multiple AI paradigms into a hybrid solution (e.g., combining neural networks and fuzzy sets into neuro-fuzzy systems) or integrating AI tools with more traditional solution techniques.

Another limitation of using AI such as genetic algorithm (GA) is the lack of ability in reaching the "optimal" solution. Also when using AI-based search methods to solve a problem, it is often hard to gain true insight into the problem and the nature of the solution, as is possible for example when using mathematical programming methods. The in- 
ability to quickly do sensitivity analyses is an important example of this limitation. The counter argument for the inability to guarantee optimality is that for hard optimization problems that defy solution using traditional optimization and mathematical programming methods, a "solution" is still better than "no solution" at all. However, there is significant empirical proof to suggest that AI-based search methods do yield "good" solutions in most cases. For gaining insight into the problem, the model may have to be rerun multiple times to assess the sensitivity of the solution to the various assumptions and parameters of the problem, which may be somewhat demanding from a computational resources or runtime standpoint.

Other known disadvantages include lack of human touch, high processing time for larger of neural networks, the system requires greater computational re-sources and sometimes prone to over fitting. The limit of applicability of AI as related to oil and gas is the imagination of the professionals using them.

\subsection{Branches of Artificial Intelligence Techniques}

\subsubsection{Artificial Neural Networks (ANN)}

An artificial neural network is the most widely used, and fast growing AI techniques used both in educational institutions and industries during recent years. ANN have the ability that mimics human attributes of problem solving that are complex to imitate using the logical, analytical techniques of expert system.

An ANN is a compilation of minor individually interconnected processing units that has certain performance characteristics in common with biological neural networks. Information is passed through these processing units along interconnections. The incoming connection is associated with two values, an input value and a weight. The output of the unit is a function of the summed value; input and the weight. Once ANN is implemented on computers, they are trained with respect to data sets until they learn the patterns used as inputs. And once trained, new patterns may be presented for prediction or classification. This technique has the ability to handle many inputs and produce suitable outcome results (Medsker, 1996). The main idea be- hind creating an ANN is to prove a simple model of human brain in order to solve complex scientific and industrial problems.

ANN can be categorised as high value and low cost tools in modelling, simulation, control, condition monitoring, sensor validation and fault diagnosis of different systems. One of the greatest advantages of ANNs over other modelling techniques is their capability to model complex, non-linear processes without any relationship assumption between the input and output variables. They learn from the data obtained from a system instead of learning from a specific program. ANNs can solve a variety of problems in optimization, pattern recognition, clustering, function approximation, time series analysis, prediction and validation. There are several ANN architectures used in literature such as multilayer perception (MLP), Back-Propagation (BP), radial basis function network (RBF) and recurrent neural network (RNN) (Haykin, 1994).

ANN as AI tool has been used to solve many problems in petroleum industry. For instance, ANN are used in reservoir characterization, optimal design of stimulation treatments, virtual measurements, drill bit selection, optimization of field operations and many more (Saputelli et al., 2002).

\subsubsection{Fuzzy Logic}

According to Zadeh (1965) statement, fuzzy logic provides a logic perspectives in AI techniques used for uncertain reasoning to mimicking aspect of human cognition. Fuzzy system as one of the branches of $\mathrm{AI}$ is more like our everyday experience as related to human decision making. It's usable in regulating and managing incomplete information or unreliable. Fuzzy logic made up of a relative simplification of a control methodology description which allows the application of a 'human language' to describe the problems and their fuzzy solutions. In many engineering control applications, the model of the system is unknown or the input parameters are highly variable and unstable. In such cases, fuzzy controllers can be applied. They are more robust and cheaper than conventional PID controllers. It is also easier to understand and modify fuzzy controller rules, which not only use human operator's strategy but, are expressed in natural linguistic terms (Kalogirou, 2003, 2007). 
Fuzzy system has been used in several petroleum engineering related applications. These applications include petrophysics, reservoir characterization, enhanced recovery, infill drilling, decision making analysis, and well stimulation.

\subsubsection{Genetic Algorithm}

Genetic algorithm is a subset of AI techniques implemented as a computerized search and optimization process that uses principles of natural genetics and natural selection. This technique encodes a potential resolution to a specific problem on a simple chromosome-like data structure. Genetic algorithms are sometimes viewed as function optimizers, even though the range of problems to which genetic algorithms have been applied is quite broad (Tate and Smith, 1995). Generic algorithm utilizes three fundamental genetic operations of selection (by selecting two chromosomes according to their fitness. The two selected chromosomes are called parents), crossover (take a copy of the selected parents and apply a crossover operation on them, with a certain probability, to produce two new children), and mutation (after the crossover operation, the two children are produced and later mutated with a certain probability to produce two new children) (Shokir et al., 2004). These operations are used to adjust the chosen solutions and select the most suitable offspring to pass on to succeeding generations.

Genetic algorithm applications has proven success hence appearing as alternatives to conventional approaches and in some cases are useful where other techniques have been completely unsuccessful. It has proved to be a promising tool solving many petroleum optimization problems, intelligent automation and real-time optimization of the entire oil and gas production process.

Genetic algorithms are also used in combination with other intelligent technologies as a hybrid system such as neural networks, expert systems, and case-based reasoning. GA shows promise but suffer from the problem of excessive complexity if applied on problems that are too large (Lakhmi and Martin 1998).

\subsubsection{Support Vector Machines (SVM)}

The SVM approach was developed in 1992 by Vanpik and collaboration at Bell Laboratories. SVM model is a set of related supervised learning methods used for classification and regression. SVM principle is based on statistical learning theory and structural minimization, which has shown to deliver higher performance than conventional empirical risk minimization used by many of the machine learning techniques (James Lara 2008).

SVM model constructs a hyper-plane or set of hyper-planes in a high dimensional space, called a feature space, which can be used for classification or regression. It advantages over other machine learning techniques include which include greater generalization capability; strong interference capacity and less learning time (Vapnik V. 1995; Anifowose and Abdulraheem 2011).

\subsubsection{Cased Based Reasoning (CBR)}

Case-based reasoning (CBR) as a subset of artificial intelligence (AI) solves problems by reuse of past experiences. CBR is an approach to problem solving and decision making where new problems are solved by finding one or more similar previously solved problems, called cases, and re-using them in the new problem situation (Aamodt and Plaza, 1994). CBR can be used on its own, or integrated with other reasoning modalities to provide more accurate outcome results by compensating the shortcomings of one approach through use of the strengths of another. CBR enables utilization of specific knowledge of previously experienced, concrete problem situations. A CBR system requires a good supply of cases in its case database. The retrieval task starts with a problem description, and ends when a best matching previous case has been found. A new problem is solved by finding a similar past case, and reusing it in the new problem situation. Sometimes a modification of the problem solution is done so as to adapt the previous solution to the unsolved case (Shokouhi et al., 2009).

There is a growing trend to employ new approaches in drilling practice to reduce operational costs in oil well by using previous experiences gained from either previously drilled wells or on wells being currently drilled. Literature revealed that Case-based reasoning has shown to provide ef- 
fective support for several tasks related to drilling. Optimization and execution of drilling process of drilling plans can be achieved through CBR. The CBR method can also used for solving operational problems which require a good description of problematic situations.

\subsubsection{Hybrid systems}

The increased popularity of hybrid intelligent systems (HIS) in recent years can be attributed to the extensive success of these systems in many realworld complex problems. The main reason for this positive result seems to be the synergy derived by the computational intelligent components, such as machine learning, fuzzy logic, neural networks, support vector machines, and genetic algorithms. Each of these methodologies provides hybrid systems with complementary reasoning and searching methods that allow the use of domain knowledge and empirical data to solve complex problems (Shabalov et al., 2012). A hybrid system which combines fuzzy logic, neural networks, genetic algorithms and expert systems are proving their effectiveness in a wide variety of real-world problems at different applications.

\section{AI Application in Oil and Gas Industry}

Oil and Gas industry is one of the biggest industries in the world with a very significant impact on the world economy. Over the years, AI has been applied and proven as a powerful and useful tool for solving practical problems in several areas of petroleum industry.

Literatures show that ANN, fuzzy logic and GA are the most popular and widely used AI tools in petroleum industry. Other includes support vector machines, functional network and cased based reasonining. Figure 1shows the early application of AI techniques between the period of 1989 till 2004, and number of research works being carried using AI tools in oil and gas industry. Some of the early applications include:
1 Interface development for simulators

2 Well $\log$ interpretation

3 Drill bit diagnosis

4 Pump operation diagnosis

5 Well test model selection and interpretation

6 Hydraulic fracturing analysis

7 Gas-lift optimization

8 Reservoir Characterization

9 PVT correlations

10 EOR project risk analysis

11 Fluid Flow in Pipes

12 Formation damage analysis

13 Reservoir characterization

14 Hydraulic fracture design and optimization

15 Oil production optimization

16 Enhance recovery management

17 Well test analysis

18 Drilling operation optimization

19 Best practices identification

20 Optimal well design using genetic algorithm 

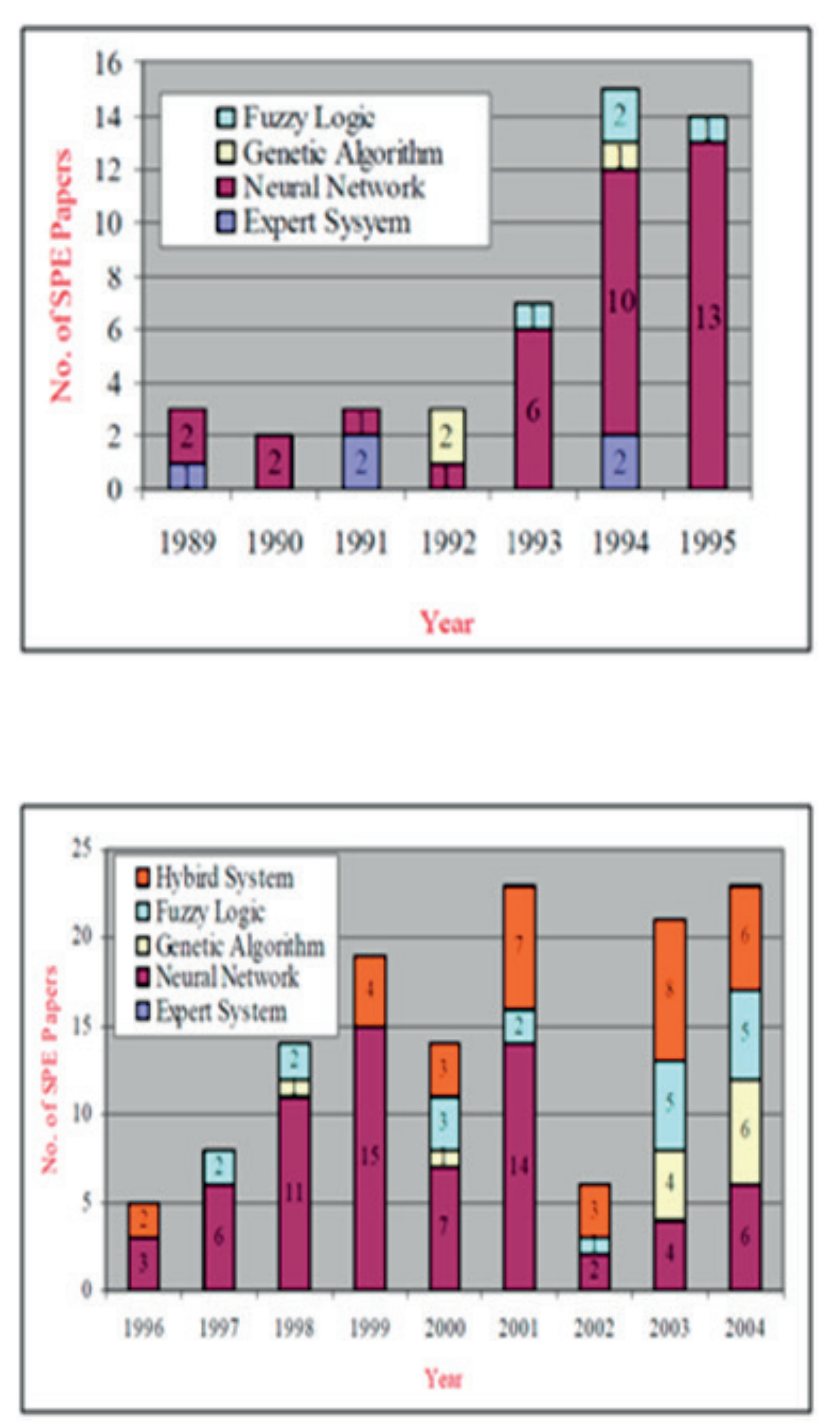

Figure 1. Early application of AI techniques tools and scientific research work carried out (Shokir, 2001)

\section{AI Applications in Drilling Sys- tem Design and Operations}

One of the major aspects of the oil and gas industry is drilling operational section. The drilling industry is a technology dependent industry. It is considered to be the most expensive operations in the world as they require huge expenses to be spent daily. Therefore, any sorts of tools that can improve the drilling operation at a minimal cost are essential and demanded during pre and post planning process of any activity. The number of publications on the application of $\mathrm{AI}$ in drilling operations in- dicates that this is a potential methodology to reduce drilling cost, increase drilling operation safety, by using previous experiences hidden in reports or known by experts.

The core objective of AI in the drilling dynamics field so far has been to accurately predict the likely performance of variant factors contributing to real-time drilling success in terms of time, safety and the adopted drilling practice. Estimation of pre-drilling settings (rig, logistics and associated drilling risks), presumptions on probable formation response while drilling (gradients, abnormal behaviors and bit conduct), 'experienced' pattern recognition and selection of specific procedural equipment (drilling, casing and tubing pipes, drilling mud and cement material) and real-time monitoring and downhole control of bit and BHA behavior (vibrations, torque limits and incident-management) have been some of the focuses of industry consultants and oil and gas experts during the recent years. For this reason, the development and up-gradation of precise generic models and efficient data processing methods is required to prescribe a near-accurate impression of drilling operations when direct and real-time data is not available.

The complexity of the drilling operations and the unpredictable operating conditions (uncertainties regarding tool/sensor response, device calibration and material degradation in extreme downhole pressure, temperature and corrosive conditions) may sometimes result in non-accurate drilling data, hereby misleading the driller about the actual downhole situation. The indulgence of smart decisionmaking models and optimized real-time controllers in the drilling system can also, therefore, provide the driller with a number of quick and intelligent propositions on key drilling parameters and on suitable preventive or corrective measures intended to bring the conditions back to an optimum drilling stage (Dashevskiy et. al, 1999).

The on-field success of AI in hydrocarbon drilling and the subsequent added interest of industry experts is a direct result of the unique systematic behavior of the AI techniques to "adapt and improvise" in drilling situations with complex, non-linear and uncertain control parameters. This behavior of AI methods is primarily due to their traits of: 
- continuous training with experience (capability comparable with human brain sensors).

- distribution and alongside processing of oncoming data (for large dynamic systems).

- handling and filtering of noise signals from data.

- generalizing the data as necessary for efficient pattern recognition and problem solving.

- classification use as well as function modelling.

- data encoding by regression or iterative supervised learning.

Drilling success, depending on prevalent conditions, is a function of several general factors. These include the selection of best technologies and tools, procedural optimization, concrete problem-solving, accurate prediction and rapid decision-making. Figure 2 shows sub-categories based on the applicability of AI in drilling operations The specific applications have been narrowed down to the presented general categories and will be explained in the next sections.

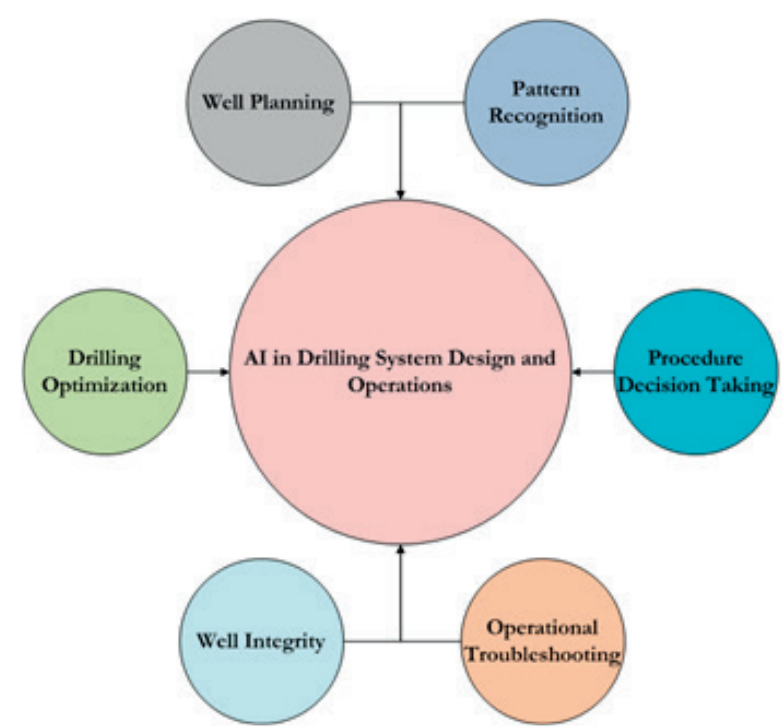

Figure 2. Application of $\mathrm{AI}$ in the drilling sector

\section{Well Planning}

Designing a well for safer and faster operations and economic budget requires complex and experiencebased decision making. Chief input information sources for an efficient well plan are normally offset well data, reservoir models and drilling simulation results. AI has been tested in different well planning phases by experts all over the world. Figure 3 shows some potential prospects as related to well planning.

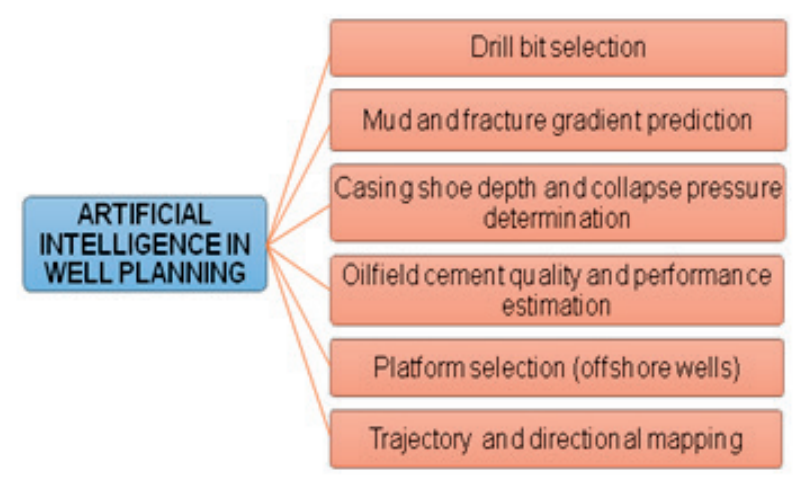

Figure 3. Potential applications of AI in well planning sector

Selection of drill bits as per formation characteristics has been one of the most prospective sectors benefiting by the application of AI (figure 4). Trained artificial neural networks (ANNs) have been an important tool for decoding data, categorizing the empirical relationships and optimized bit selection based on user defined information database. The database may include IADC bit codes for typical rock formations, rock strength data, geology, compaction characteristics and conventional ROP values corresponding to the rocks. Hence after the user input on the data, the ANNs have the ability to correctly learn the codes and numerical values and select the suitable bit for a particular drilling environment, whether it's a PDC, roller cone, diamond insert or a hybrid.

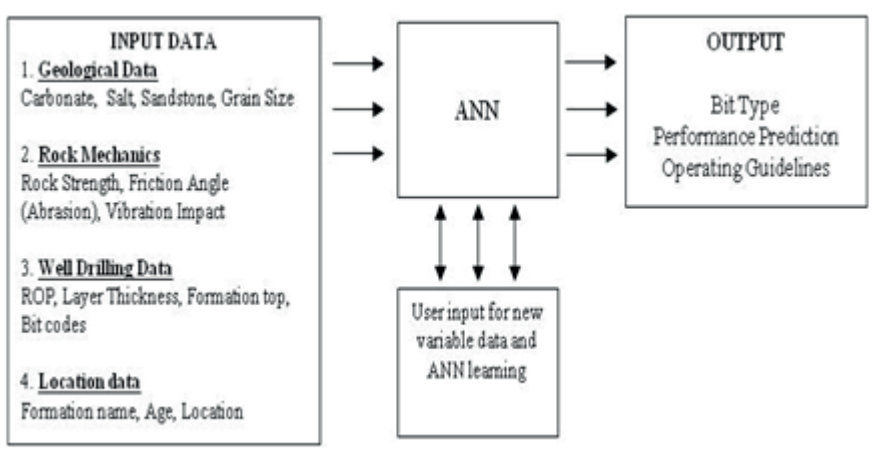

Figure 4. Base layout for drill bit selection by ANNs (National Oilwell Varco, 2013)

Mud and fracture gradient prediction by neural network system (preferably GRNNs) has yielded quite accurate results over the last decade, poten- 
tially in oil fields of Mid-eastern regions with adjacent oil and water bearing formations and very selective production and injection. In fact, some experts regard GRNNs more accurate and reliable than the conventional methods (D-exponent, Comb, Ben Eaton etc.). In most cases, the GRNNs are trained to predict the approximate gradients as a function of depth, overburden gradient and Poisson ratio. The neural network model takes all this data as input (can be actual field data or approximations by other techniques) and plots the predicted mud and/ or fracture gradient for the data set. However, care has to be taken to use the prediction only for the specified range of data. Being strongly dependent upon the range of input data, any extrapolations for greater depths may lead to serious errors and inaccuracies (Sadiq and Nashwi 2000).

Casing collapse occurrence and depth determination can also take neural network approach using a simple spreadsheet program with BPNN basis. As previously used in Middle-east and Asian countries, a back-propagating network of user-defined number of internal (hidden) layers can be connected to input and output layers to provide an 'experienced' estimate on casing collapse depth for the wells to be drilled. The data layer can have a number of inputs such as location, depth, pore pressure, corrosion rate, casing strength etc. to analyze and provide feed on expected collapse depth and probability of casing collapse (e.g. in years). A basic layout of the method is provided in figure 5. However, the approach is relatively new and still needs further up gradation on its result accuracy and generalization of input data.

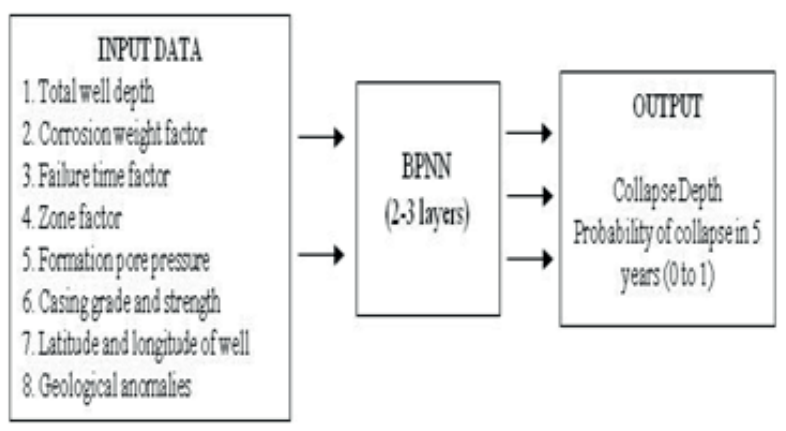

Figure 5. Base layout for casing collapse and depth prediction by BPNNs

Quality and performance of oilfield cements slurries can also be estimated in terms of composition, particle size distribution and thickening time (neat and retarded) using the Diffuse Reflectance Infrared Fourier Transform (DRIFT) spectrum of cement powders. The method uses artificial neural networks (ANNs) for prediction on slurry performance. The base idea is to have a database that establishes an infrared spectrum of the cement powder as a signature of its behavior. The spectrum can then provide very specific and refined information about the nature and state of the cement that is not provided in API tables (presence of contaminants, particle size distribution, cement ageing, presence of non-API cements etc.).

The first database based on this approach created by Schlumberger in 1994 contained detailed information from 158 cements worldwide (mainly on classes $\mathrm{A}, \mathrm{G}$ and $\mathrm{H}$ ) and included empirical data on their general composition, oxide composition, lime content, loss on ignition (LOI), insoluble residue content, surface area, particle size distribution and diameters, thickening time curves for neat and retarded slurries and diffuse reflectance spectra. Models were later constructed to predict specific cement properties and quality with the entire diffuse spectra as the input (Fletcher et al., 1994).

Selection of offshore platform requires skilled decision making based on many diverse factors such as location, water and well depth, expected production rates, cost, operator experience and anticipated weather and tidal conditions. Wang et al. (2011) developed a model based on BP artificial neural networks for deepwater floating platform selection. An approach for case-specific selection of best suited offshore units (SPAR, TLP, FPSO or semisubmersible) using non-linear BPNNs with multiple (nine) input nodes and one processing (hidden) layer encompassing five model functions (technology maturity, field development time, cost, operator experience and risk involved). A simple layout of the network is shown in figure 6 . 


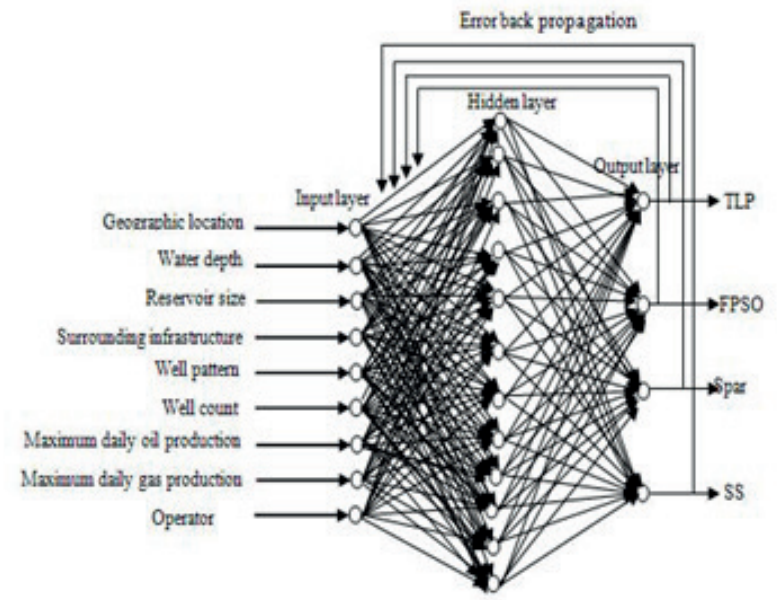

Figure 6. Base layout for offshore platform selection by BPNNs (Wang et al., 2011)

To improve the data convergence and processing speed, Levenberg-Marquardt (L-M) algorithms were later used to improve the BP network. The improved BP model yielded an accuracy of over $70 \%$ for 10 initial sample datasets with very limited errors. The results retrieved from the model for platform selection for the West African field of Egina were in accordance with expected results. The method, thus, provided a quantitative approach for selection of deepwater floating platforms all over the world. Further up gradation and optimization of the model is in progress.

Trajectory and directional planning has also benefited by the development of generic algorithms and application of fuzzy theory (case based reasoning), especially for offshore well design. For example, Mendes, Guilherme and Morooka (2001) created a dataset of specific offshore drilling information using fuzzy reasoning. They later implemented a generic algorithm to predict feasible trajectories for wells and relevant directional details using the retrieved similar cases from the dataset. However, for accuracy purposes, the predictions need to be validated via software simulations for further assurance.

\subsection{Real Time Drilling Optimization}

The pre-drilling processes of well planning are in a close and partially inter-convertible relation with real-time optimization procedures. Many such methods fall into well planning or real-time optimization category depending upon whether they are carried out prior to drilling (with offset or model data) or while drilling (using actual data feed from the well).

Optimization of drilling process is primarily related with improved monitoring of downhole parameters (ROP, BHA response, DS vibrations, bit performance etc.) for reduced drilling uncertainty and enhanced confidence. Where the application of intelligent networks, algorithms and case-based reasoning has profited well planning phases, it has been equally valuable in optimizing the drilling performance and diagnosing the barriers hindering efficient drilling in real-time. Some important uses have been mentioned in figure 7 .

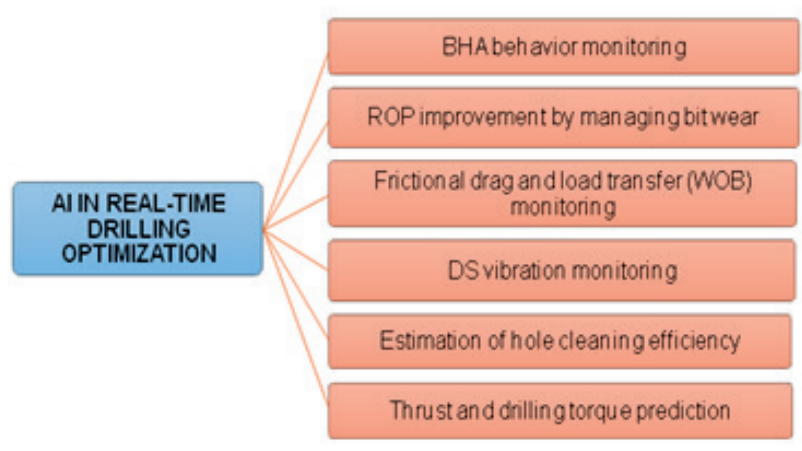

Figure 7. Important applications of $\mathrm{AI}$ in drilling optimization

The presence of frictional drag is a phenomena hindering the forward motion of drill bit, especially in horizontal, ERD and slanted wells, despite the use of sophisticated BHAs including motors, circulation subs and lubrication components in mud. The induction of extensive friction torque if not precisely estimated and counteracted upon, can lead to grave issues such as unscrewed joints, broken or damaged BHA sections or even helical buckling of the DS which might be complicated to unbuckle. Estimation of frictional drag in horizontal sections during well planning phase or even in real time before reaching the target section can help evade expensive trips to replace BHA tools or to rectify a locked-up drillstring. This is where the application of ANNs has proved to be helpful for accurate prediction of frictional drag and DS contact force during slack-off load transmission. A two-hidden-layer BPNN with adequate training is able to determine the bottom contact force and frictional drag as a function of radial clearance (between the string and hole wall), slack-off load, bending stiffness of DS and other elasticity parameters. The error percent- 
age in output parameters (between model and actual field results), after repeated simulations in training phase, has been minimum from $0-4 \%$ (Sadiq and Gharbi, 1998).

Hole-cleaning predictions in underbalanced drilling techniques (air drilling, foam drilling etc.) are aimed to minimize formation damage, bit and stabilizer issues and other drilling problems. Estimation of hole cleaning efficiency in terms of cutting concentration (in \%) in the wellbore annulus can be made using BPNNs or Multiple Linear Regression (MLR) methods as a function of parameters highlighted in Table 1.

A comparison of the results obtained from BPNNs and MLR depicts pronounced error reduction using BPNNs, showing improved ability of ANNs in prediction compared to other computational techniques (Rooki et al., 2014).

Table 1. Input parameters for hole cleaning evaluation using BPNNs or MLR

\begin{tabular}{|l|l|}
\hline Input Parameters & Output Parameter \\
\hline Wellbore Size \& geometry & \\
Drilling RPMs & \\
Annular velocity & \\
Quality (for foam drilling) & Cutting \\
Wellbore eccentricity & Concentration \\
Temperature & (in \%) in the \\
Bottom Hole Pressure & well bore \\
Cutting Size & \\
ROP (average \& Max.) & \\
Mud density \& viscosity & \\
Pump rate & \\
\hline
\end{tabular}

Drillstring vibrations (axial, lateral, and torsional) are a frequent problem hindering smooth and optimum drilling conditions. The interaction of drill bit and BHA with the borehole walls results in bit bounce, backward / forward whirl and overtorqued joints, causing damaged BHA parts, increased non-productive time and significant decline in the drilling rate. However, monitoring of drilling parameters influencing the growth of vibrations can help the driller to improvise on base control parameters (RPM, WOB, TOB etc.) as necessary to avoid vibration conditions, optimize the drilling procedure and maintain the ROP. An understanding of the interaction of various drilling parameters generating DS vibrations and the case-specific influence of different parameters in their intensification requires means of recognizing complex behaviors, patterns and relationships between control parameters. This is where ANNs have been successful in ROP modelling and predicting the behavior of control parameters towards the possible accumulation of vibrations. Introduction of control parameter (Surface and downhole RPMs, WOB, DS formulation, TOB, static and dynamic downhole friction components, formation UCS, Poisson ratio and elastic modulus) values in a system trained to identify complex patterns in order to determine the probability of DS vibrations can not only be used to model the vibrations in well planning phase but also to manage them in real-time and maximizing the ROP. The system can be trained either by analyzing vibration data from historical cases or by running simulations on an experimental setup (Esmaeili et al., 2012).

ANNs, with their continuous learning and refined predicting capabilities, are also the next step forward in the development and up-gradation of DS behavior modelling devices and real-time BHA monitoring tools. Selection of appropriate operating parameters is, of course, a complicated task for modelling a non-linear, multi-output, dynamic drilling system. However, real-time historical DS dynamics data from MWD and LWD tools (MWD / LWD reports) and downhole sensor data for dynamic state of BHA during field tests in various drilling scenarios can be of vital importance in the assortment of control parameters and in developing the database for the tool. The selected input-output parameters (DS, borehole, drill-mud and formation characteristics), along with the generated datasets, can be used for training of the ANN tool. Experiments and tests based on the approach have depicted encouraging results due to the general agreement between the modelled response and actual measured BHA response. Furthermore, repeated tests and research has also laid down general-purpose criteria for selection of critical input-output parameters and for representative data for database building $\&$ for training of the tool (Dashevskiy et al., 1999).

ROP improvement is essentially related to keeping the drill bit parameters compatible with the formation geology and the borehole conditions. To enhance downhole bit hours and improve the overall ROP efficiency, it is crucial for the rig-site drilling 
engineers to make well-informed decisions based on a combination of both live well feed and offset well data. To achieve this, an ANN bit usage optimization system can be developed to check bit compatibility with the formation and to manage control parameters based on real-time data to ascertain the maximum possible bit running length at the highest feasible drilling rate. Such a tool can help attain extended bit and BHA tool life and lesser NPT by reducing the number of trips. The input rock, DS and bit parameters for the tool development can be chosen based on the well feed and offset log information on downhole lithology and conditions, and the tool can be trained for the current bits' (chosen during the planning phase) specific structure, material, geometry and wear rate. Improvisations can then be made to maximize the bit life by managing its dull condition and the drilling efficiency by increased ROP (Gidh et al., 2012).

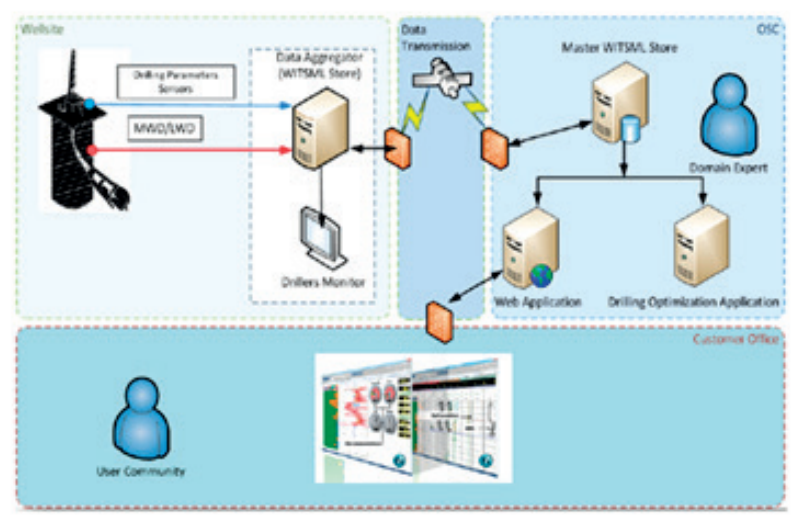

Figure 8. Figure 8: Basic workflow of the tool and data transfer mechanism (Gidh et al., 2012)

\subsection{Well Integrity}

The focus of artificial intelligence has not evaded the difficulties faced in maintaining a stable wellbore while drilling due to complex lithology and abnormal pore pressure values. In many instances, these discontinuities and stressed conditions lead to many wellbore issues such as lost circulation, downhole kicks, wellbore leakages (drillstring or casing) and even stuck-pipe situations. To assist in sustaining the well integrity, AI tools such as ANNs and fuzzy reasoning can be employed to analyze the stability of the designed / being-drilled wellbore in a particular in-situ stressed environment having a specific geological order and rock strengths, a definite hydrostatic and fracture gradient, assigned drilling fluid properties and distinct configuration of drillstring (parameters taken as input feed). The stability results achieved as the output for historical test cases are compared with actual field results to determine the level of agreement between them, imparting increased reliability and confidence in the applicability of the tool. Further up-gradation in the tool by considering additional failure mechanisms (corrosion reactions, thermal degradations, mechanical collisions) can enable the experts to evaluate the instability risk on the designed wellbore at a particular depth (or formation) well before-hand for early preparations and to even use added optimized algorithms to list all possible root-causes of the problem for technical alterations in the design in good time. A visual clarification on how well stability prediction technique may work using an ANN is shown in figure 9 .

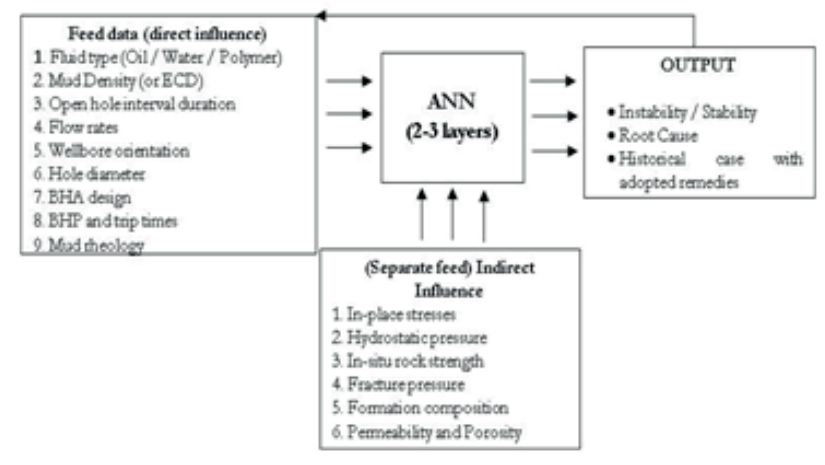

Figure 9. Predicting wellbore instability by ANNs (Jahanbakhshi and Keshavarzi 2012)

\subsection{Operational Troubleshooting}

Despite proper well-planning, use of downhole data sensors, optimized procedures and expert rig crew, drilling issues occur when drilling deep, or directional. Most of the minor problems occurring while drilling an interval are resolved through technical referral of real-time data documents, such as the daily drilling reports (DDRs), end of interval reports (EOIRs) and end of well report (EOWR). These data documents, in later instances, are the basis for formulation of large databases and information portals that serve as the basis for applicability of AI tools such as ANNs and fuzzy reasoning devices. In the recent years, a frequently encountered drilling hitch that has been significantly reduced with the aid of AI tools is the differential sticking of the drill pipe. The research work 
to accurately predict stuck pipe before reaching the region of concern has considerably increased after 2006 and a lot of reference datasets have been developed for pre-estimation of stuck pipe as well as for quantifying the force for freeing the stuck pipe. Furthermore, AI methodologies for determination of the free point on the string for fishing of the stuck section are being built and upgraded over the last three years.

As derived by experts, the most feasible approach for prediction of differentially (or mechanically) stuck pipe is, yet again, through the use of ANNs. The ANN or BPNN tools developed after 2011 are able to accurately forecast the risk of stuck pipe at a depth region not only during well planning but also in real-time. Analyzing the input through a database with DDR, EOIR and EOWR data from hundreds or thousands of wells and using a network of 2-3 fully interconnected feed forward hidden layers (with back propagation learning rule), convolutional models based on constraints of several drilling variables have been developed and have been observed to automatically detect the control parameters of concern. These parameters can then be altered as per expert opinion to avoid the problem in real-time. In order to test the accuracy and error percentage, a series of test trails or simulations on already drilled cases can be run (Shadizadeh et al., 2010).

For illustrative and explanatory purposes, the output can also be shown in a well-log form along with the variation in several input parameters (Siruvuri et al., 2006). A simplified layout summarizing the technique is presented in figure 10. Sample input parameters such as differential pressure; mud plastic viscosity, $\mathrm{pH}$, chloride content, gel strength, yield point, drilling ROP, mud annular velocity, RPMs and geometric factor have been plotted with the probability of stuck pipe in the last log table. This provides an opportunity of real-time monitoring of probable stuck pipe conditions, understanding its source and prevention measures and, if successfully prevented, saving a lot of cost capital on fishing procedures.

In case of fishing operations, a similar approach using ANNs can also be utilized to estimate the free point on the stuck pipe. Similar to the above method, the model will require mud properties, RPM, ROP and some base control data to analyze it through fishing operations report data from numerous wells with acceptable accuracy. The system can also benefit wireline logging time reduction during drilling (Nejad and Shahbazi 2013).
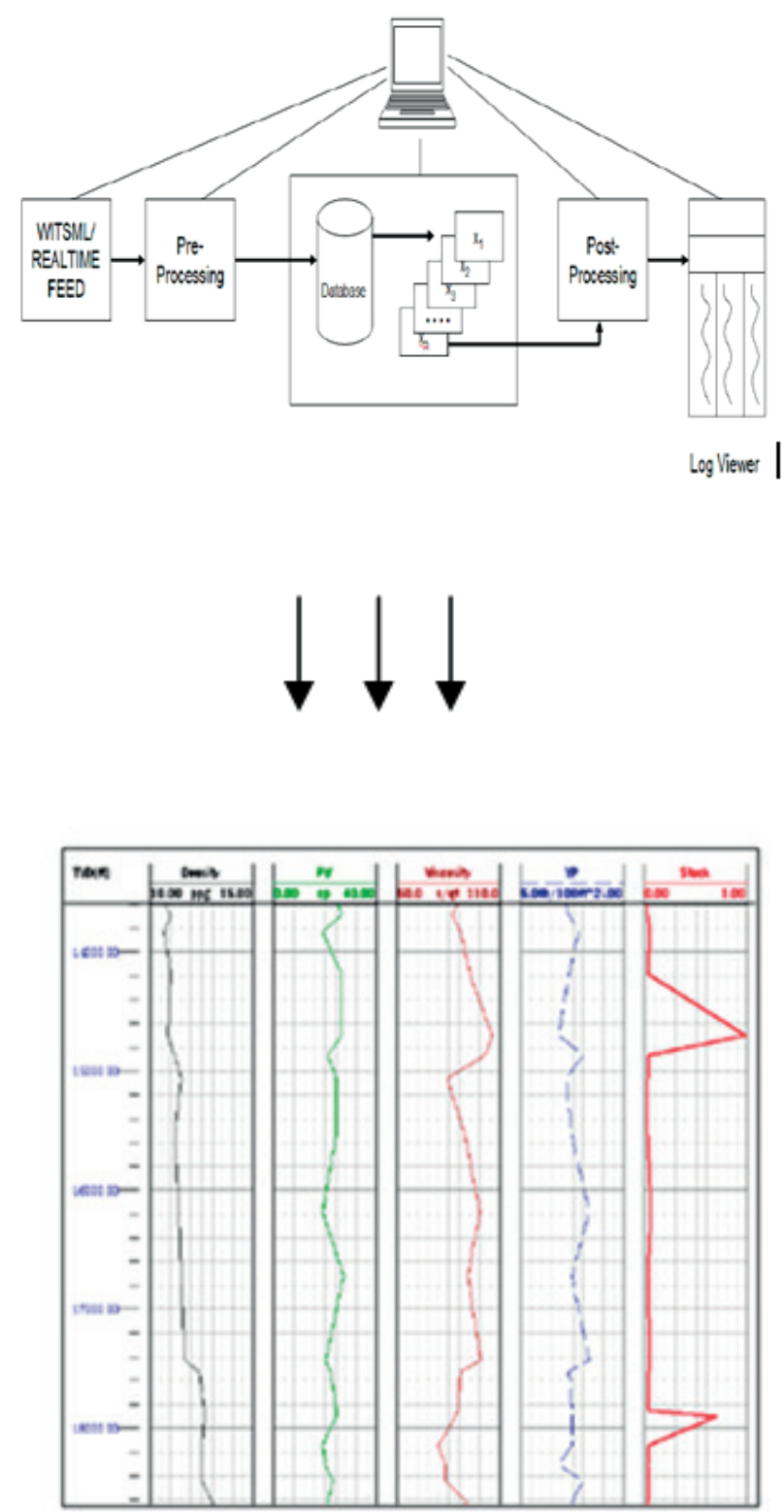

Figure 10. Real-time data feed, processing and log-plot output from network (Siruvuri et al., 2006)

\subsection{Pattern Recognition}

In systematically intelligent tools, irrespective of the approach (ANNs, CBR or generic algorithms), the basis for evaluation of parameters is a vast dataset consisting of relevant information on 
hundreds or thousands of historical cases. This implies that whenever a new problem in a specific drilling sector emerges, a formatted case-study is built and added to the database along with the previous events. A sequential feed of such data (orderly arranged by well depths, dates, area, costs or adopted procedures) provides a smart system that can compare an input feed to a particular range of data and leave out the rest of database to reduce error risk and increase decision accuracy. For example, an input feed for a well $900 \mathrm{~m}$ deep will only be evaluated by the data in the range shallow wells and will not process it through the data on midrange and deep wells. Such prediction methodology has been further developed and upgraded to intellectually recognize input feeds and evaluate them for specific datasets. Over the years, based on this technique, modelling systems and inspection methods have been developed and utilized in the drilling industry, some of which are mentioned below (figure 11).

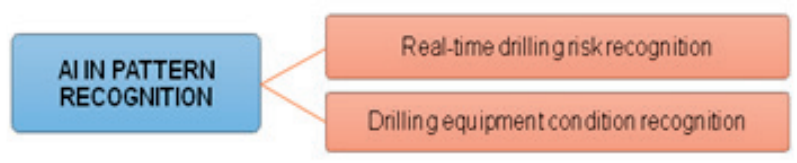

Figure 11. Application of AI in case-based pattern recognition and improvisation

Real time drilling risk indication is a key factor in pre-estimating possible drilling incidents, determining their root causes, evaluating the level of risk associated, suggesting prevention or control measures and modifying control parameters as necessary to evade the situation. For real time detection, it is critical for the AI tool system to be able to detect major fluctuations from the real-time feed of data that is being transmitted from the storage computer (or directly from field sensors). Lian, Zhou and Huo (2010) labelled this advanced recognition technique as the signal changing tendency rate automatic extraction technology. Based on fuzzy (or case-based) reasoning method, a base comparison of live-feed with the database reference sets and prompt indication on deflection between the actual and reference function values can estimate drilling risk in early time and can even be applied for live downhole monitoring of control parameters. Even a base comparison with such a reasoning system having a vast database with a wide range of incident-prone values of control parameters (hook load, WOB, downhole torque, RPMs) can provide continuous average risk values with occasional peaks and compare it with maximum and minimum base references for accurate and reliable drilling risk detection. One simple example for application of such a system would be an early indication of downhole kick by prompt detection of rapid and intense fluctuations in the feed from flow-rate sensors and then later from gas level (in mud) surveying sensors (Lian et al., 2010).

The developed drilling equipment condition recognition tool is primarily based on a ANN system that determines the state of the drilling system by evaluating the condition of the drilling components (drillstring, drill bit, surface equipment, mud etc.) with respect to the formation being drilled and control parameters (WOB, RPMs and mud flow rate) in place (either real-time or modeled) to optimize the drilling efficiency. Like other systems, the technique is based on the comparison and intelligent detection of the input data from a wide range of datasets and comparisons between the fed data and the information from previous case histories. After initial training of the network system, it takes in the above mentioned control data in a digital format (can also be directly from field sensors via storage computer) and, based on the selected equipment (bit, MWD tool, motor, pumps, RSS etc.) estimating the downhole condition in real-time (Yamaliev et al., 2009). For example, the application for condition evaluation of an insert bit in a hard environment is visually elaborated in figure 12. Similar predictions can be obtained for other drilling equipment with the AI tool.

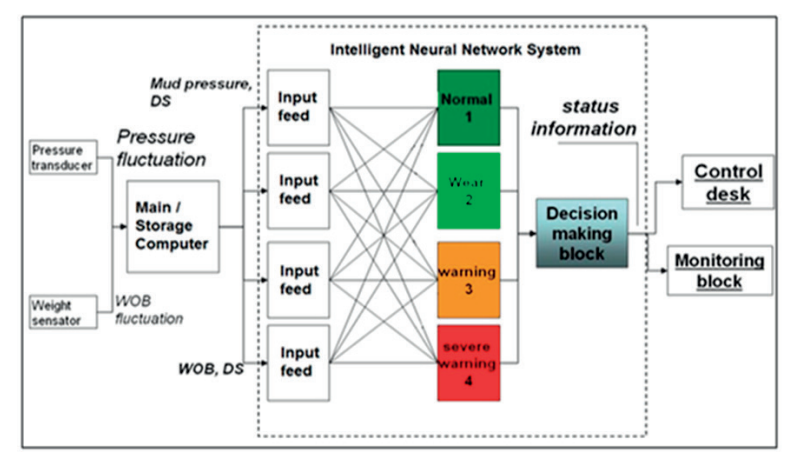

Figure 12. Detection of bit condition based on drilling environment and control parameters using intelligent AI tool 


\subsection{Procedural Decision-Taking}

The selection of feasible drilling procedures (underbalanced, overbalanced, jet drilling etc.) and sub-methods in terms of improved production, reduced costs, time saving and technical compatibility is always critical to the final well condition and requires in depth consideration of many drilling parameters beforehand. One of such decisions is the choice of drilling in unconsolidated sandstone reservoirs (foam, air or wash-back) to avoid the undesirable flow of loose sand particles into the well and cause jamming of pump. Popa, Malamma and Hicks (2008) applied case-based reasoning (CBR) to aid in the selection of the optimum hole-cleaning procedure in shallow unconsolidated sands. For reasoning evaluation, a database containing detailed information on production operations and well interventions from nearly 5000 wells was built over a period of almost three years. To improve the decision reliability and provide factual evidence for reasoning on the proposed solution, a small data-set of renown case-studies (on adopted procedures in loose sands) was collected. Initial test runs on a random set of case-studies yielded $80 \%$ similarity between the methods proposed by the AI tool and the ones actually implemented on the field by experts. However, the tool is under further up-gradation and revision before being actually employed by the operators for aid in crucial decision-making.

\section{Current Technology Gaps of AI Applications in Drilling System Design and Operations}

With the recent successful implementation and result of $\mathrm{AI}$ as intelligent systems tools in $\mathrm{E} \& \mathrm{P}$ industry, it is becoming explicit that our industry has realized the importance applicability of the intelligent model solving several disciplinary related problems.

The technique has been successfully used in areas of drilling for prediction, monitoring, forecasting and many other area but has not been utilized the decision making of drilling equipments/machineries. There is a need for further research for development of AI applications in drilling equipments or materials method selection. To date, there exist no literature or research works done or adopted to drilling equipments/machineries used during the drilling process of a well.

As the drilling industry is a technology dependent industry. Therefore, any sorts of tools that can improve the drilling operation, most especially for candidates selection of equipment are essential and are demanded during planning and during plan execution. With various drilling equipments and materials available in the market and advancement in technology being integrated in many rig system for safety, better performance and cost effective, care must be taken in choosing the right material or equipments meeting the needs.

As every decision-making process provides a final option and requires identifying options beforehand. The application can add value to operations and serve as guide on which equipments or machineries to use as related to drilling system design and operations. A good implementation of artificial intelligence techniques will inevitably lead to facilitating solution of repetitive problems and improves the reasoning in making the right choice and solving the long standing problems in the selection of drilling materials or equipments.

\section{Summary}

Among the broader applications of AI methods, ANN, BPNN and CBR are widely used in drilling practices. Table 2 lists application of AI techniques and their purposes since their emergence in drilling operation area of oil and gas.

\section{Conclusions}

Through this review work, it has been pointed out that the AI methodology in the oil and gas industry has been employed by different segments in petroleum industry. Its techniques and applications have makes huge impact at different applications leading to time saving, minimizing risk, saving cost, improving efficiency and solving many optimization problems.

The oil and gas industry today has made extensive progress in improving the drilling performance by adding high-tech downhole tools and sensors, modifying classical drilling procedures and using state-of-the-art surface rig systems. However, little 
Table 2. Timeline AI techniques application in drilling practices

\begin{tabular}{|c|c|c|c|c|}
\hline $\begin{array}{l}\text { Drilling } \\
\text { Sector }\end{array}$ & Application & $\begin{array}{l}\text { AI Ap- } \\
\text { proach }\end{array}$ & Researcher(s) & Year \\
\hline \multirow{6}{*}{$\begin{array}{l}\text { Well Plan- } \\
\text { ning }\end{array}$} & Bit selection & ANN & National Oilwell Varco & 2013 \\
\hline & Gradient prediction & GRNN & Sadiq and Nashwi & 2000 \\
\hline & $\begin{array}{l}\text { Casing collapse } \\
\text { prediction }\end{array}$ & BPNN & $\begin{array}{l}\text { Salehi, Hareland, Ganji, Keivana and Abdol- } \\
\text { lahi }\end{array}$ & 2007 \\
\hline & $\begin{array}{l}\text { Cement quality } \\
/ \quad \text { Performance } \\
\text { estimation }\end{array}$ & ANN & Fletcher, Coveney and Methven & 1994 \\
\hline & $\begin{array}{l}\text { Offshore platform } \\
\text { selection }\end{array}$ & $\begin{array}{l}\text { Hybrid } \\
\text { (BPNN- } \\
\text { GA) }\end{array}$ & Wang, Duan, Liu and Dong & 2011 \\
\hline & $\begin{array}{l}\text { Directional map- } \\
\text { ping }\end{array}$ & CBR & Mendes, Guilherme and Morooka & 2011 \\
\hline \multirow{5}{*}{$\begin{array}{l}\text { Procedural } \\
\text { Optimiza- } \\
\text { tion }\end{array}$} & BHA monitoring & ANN & Dashevskiy, Dubinsky and Macpherson & 1999 \\
\hline & Bit wear control & $\overline{\mathrm{ANN}}$ & Gidh, Purwanto and Ibrahim & 2012 \\
\hline & $\begin{array}{l}\text { Drag and slack-off } \\
\text { load prediction }\end{array}$ & ANN & Sadiq and Gharbi & 1998 \\
\hline & $\begin{array}{l}\text { DS vibration con- } \\
\text { trol }\end{array}$ & ANN & Esmaili, Elahifar, Thonhauser and Fruhwirth & 2012 \\
\hline & $\begin{array}{l}\text { Hole cleaning effi- } \\
\text { ciency estimation }\end{array}$ & BPNN/MLR & Rooki, Ardejani and Moradzadeh & 2014 \\
\hline $\begin{array}{l}\text { Well Sta- } \\
\text { bility }\end{array}$ & $\begin{array}{l}\text { Kick, loss, leakage } \\
\text { monitoring }\end{array}$ & ANN & Jahanbakhshi and Keshavarzi & 2012 \\
\hline \multirow[t]{3}{*}{$\begin{array}{l}\text { Problem- } \\
\text { Solving }\end{array}$} & $\begin{array}{l}\text { Stuck-pipe control } \\
\text { and corrective mea- } \\
\text { sures }\end{array}$ & $\begin{array}{l}\text { BPNN / } \\
(\text { ANN-GA) } \\
\text { Hybrid }\end{array}$ & Shadizadeh, Karimi and Zoveidavianpoor & 2010 \\
\hline & & & Siruvuri, Nagarakanti and Samuel & 2006 \\
\hline & & & Nejad and Shahbazi & 2013 \\
\hline \multirow{2}{*}{$\begin{array}{l}\text { Pattern } \\
\text { Recogni- } \\
\text { tion } \\
\end{array}$} & $\begin{array}{l}\text { Real-time drilling } \\
\text { risk }\end{array}$ & FR / CBR & Lian, Zhou, Zhao and Hou & 2010 \\
\hline & $\begin{array}{l}\text { Drilling equipment } \\
\text { condition }\end{array}$ & ANN & Yamaliev, Imaeva and Salakhov & 2009 \\
\hline $\begin{array}{l}\text { Critical } \\
\text { Decision } \\
\text { Making }\end{array}$ & $\begin{array}{l}\text { Determination of } \\
\text { feasible drilling } \\
\text { procedure as per } \\
\text { drilling conditions }\end{array}$ & CBR & Popa, Malma and Hicks & 2008 \\
\hline
\end{tabular}


progress has been made on optimizing the adopted drilling processes based on the ever-valuable historical and offset drilling data available. Equipping the driller and engineers with concrete and rapid decisions based primarily upon real-time offset or casebased field data is now the key to increased operating efficiency and lower costs. The indulgence of artificial intelligence in drilling decision making is, thereby, aimed to provide the decision-makers onspot precise and accurate information on downhole drilling conditions by replacing the repeatedly erroneous human factor in applying base control variables such as WOB, RPM, mud rheology, rig settings and many more.

The prime benefit of employing AI tools to guide the planning, optimization and problemsolving aspects of the drilling process is the rational on-field decision making based purely on documented field evidence. The overall results on the implementation of ANNs, fuzzy tools, generic algorithms and support vector machines in drilling assessment, whether in modelled comparisons or in test field trials, have so far been highly encouraging and demand dedicated research and development of the AI tools for professional industrial usage and trend-setting. This, in terms, can lead to substantial drilling improvements such as economic and effective rig and DS selections, consistent maximum feasible ROP throughout drilling, extended bit and tool life, highly reduced NPT, increased wellbore stability, reduced real-time procedural risks and efficient and accurate management of complicated drilling incidents.

\section{Abbreviations}

$\begin{array}{ll}\text { AI } & \text { Artificial Intelligence } \\ \text { E \& P } & \begin{array}{l}\text { Exploration and Production } \\ \text { Back Propagation Neural Net- } \\ \text { BPNN }\end{array} \\ \text { GRNN } & \begin{array}{l}\text { General Regression Neural Net- } \\ \text { work }\end{array} \\ \text { ANN } & \text { Artificial Neural Network } \\ \text { DS } & \text { Drill String } \\ \text { CBR } & \text { Case-Based Reasoning }\end{array}$

\begin{tabular}{|c|c|}
\hline PVT & $\begin{array}{l}\text { Pressure-Volume- } \\
\text { TemperatureEOR Enhanced } \\
\text { Oil Recovery CBR Case Based } \\
\text { Reasoning }\end{array}$ \\
\hline FR & Fuzzy Reasoning \\
\hline GA & Genetic Algorithms \\
\hline SVM & Support Vector Machine \\
\hline MLR & Multiple Linear Regression \\
\hline GRNN & $\begin{array}{l}\text { General Regression Neural Net- } \\
\text { work }\end{array}$ \\
\hline EOIR & End of Interval Report \\
\hline EOWR & End of Well Report \\
\hline DDR & Daily Drilling Report \\
\hline ERD & Extended Reach Drilling \\
\hline MWD & Measurement While Drilling \\
\hline LWD & Logging While Drilling \\
\hline CSD & Casing Drilling \\
\hline
\end{tabular}

\section{References}

[1] A. Aamodt, E. Plaza, Case-Based Reasoning: Fundamental Issues, Methodological Variations, and System Approaches. Artificial Intelligence Communications, Vol. 7, No. 1, pp. 39-59, 1994.

[2] F. Anifowose, A. Abdulraheem, Fuzzy LogicDriven and SVM-Driven Hybrid Computational Intelligence Models Applied to Oil and Gas Reservoir Characterization. Journal of Natural Gas Science and Engineering 3, 2011.

[3] Bhattacharyya Pushpak, Introduction to Artificial Intelligent, 2011.

[4] D. Dashevskiy, V. Dubinsky, J.D Macpherson, Application of Neural Networks for Predictive Control in Drilling Dynamics. SPE 56442, Baker Hughes and University of Houston, 1999.

[5] A. Esmaeil, B. Elahifar, G. Thonhauser, R.K. Fruhwirth, ROP Modeling using Neural Network and Drill String Vibration Data. SPE 163330, University of Leoben, 2001.

[6] P. Fletcher, P.V. Coveney, C.M: Methven, Predicting The Quality and Performance of Oilfield Cements using Artificial Neural Networks and FTIR Spectroscopy, SPE 28824, 1994.

[7] Gentry Braswell, Artificial Intelligence Comes of Age in Oil and Gas. Journal of Petroleum Technology, Issues 2013-01, 2013.

[8] Gharbi et al. 2005. An Introduction to Artificial Intelligence Applications in Petroleum Exploration and Production. 
[9] Y. Gidh, A. Purwanto, H. Ibrahim, Artificial Neural Network Drilling Parameter Optimization System Improves ROP By Predicting/Managing Bit Wear. SPE 149801, Smith Bits, 2012.

[10] Jianhong, Artificial intelligence and data mining: algorithms and applications, 2003.

[11] Jack V. Tu, Advantages and Disadvantages of Using Artificial Neural Networks versus Logistic Regression for Predicting Medical Outcomes. Journal of Clinical Epidemiology, 1996.

[12] R. Jahanbakhshi, R. Keshavarzi, Intelligent Prediction of Wellbore Stability in Oil and Gas Wells: An Artificial Neural Network Approach. ARMA 12243, Islamic Azad University, Tehran, Iran, 2012.

[13] James Lara, Artificial Neural Networks for Therapeutic Protein Engineering. Medicinal Protein Engineering. CRC Press, Dec 1, 2008.

[14] S.A.Kalogirou, Artificial Intelligence for the Modelling and Control Of Combustion Processes: A Review. Prog Energy Combust Science 2003; 29:515-66, 2003.

[15] S.A. Kalogirou, Artificial Intelligence in Energy and Renewable Energy Systems. Nova Publisher; 2007; 1-60021-261-1, 2007.

[16] V. Kecman, Learning and Soft Computing, Cambridge, Massachusetts, MIT Press, 2001.

[17] C.J. Lakhmi, N.M. Martin, Fusion of Neural Networks, Fuzzy Sets and Genetic Algorithms: Industrial Applications. ISBN:0849398045, 1998.

[18] Lian, Z., Zhou, Y., Zhao, Q., Hou, Z. 2010. A Study on Drilling Risk Real Time Recognition Technology Based on Fuzzy Reasoning. SPE 131886.

[19] Larry R. Medsker, Hybrid Intelligent Systems, 1995.

[20] L.R Medsker, Microcomputer Applications of Hybrid Intelligent Systems. Journal of Network and Computer Applications. Volume 19, Issue 2, Pages 213-234, April 1996.

[21] Mellit Adel, Artificial Intelligence Technique for Modeling and Forecasting Of Solar Radiation Data: A Review. Journal International Journal of Artificial Intelligence and Soft Computing archive Volume 1 Issue 1, Pages 52-76, 2008.

[22] A. Mellit, S.A. Kalogirou, L. Hontoria, S. Shaari, Artificial Intelligence Techniques for Sizing Photovoltaic Systems: A Review. Renewable and Sustainable Energy Reviews, 2008.
[23] Mohamed Benghanem, Artificial Intelligence Techniques for Prediction of Solar Radiation Data: A Review. International Journal of Renewable Energy Technology Issue Volume 3, Number 2/2012.

[24] National Oilwell Varco, Research paper. 2013. Drill Bit Selector, October 2013.

[25] A.S Nejad, K. Shahbazi, Petroleum University of Technology, Ahwaz, Iran, International Journal of Computer Applications (0975-8887), 2001.

[26] D. Patterson, Introduction to Artificial Intelligence and Expert Systems. Prentice Hall, Inc, 1990.

[27] A. Popa, C. Malamma, J. Hicks, Case-Based Reasoning Approach for Well Failure Diagnostics and Planning. SPE 114229-MS, SPE Western Regional and Pacific Section AAPG Joint Meeting, Bakersfield, California, USA, 29 March-2 April 2008.

[28] R. Rooki, F. D. Ardejani, A. Moradzadeh, Hole Cleaning Prediction in Foam Drilling using Artificial Neural Network and Multiple Linear Regression, Birjand University of technology, Iran, 2014.

[29] T. Sadiq, I.S Nashwi, Using neural networks for prediction of formation fracture gradient, Kuwait University, 2000.

[30] T. Sadiq, R. Gharbi, Prediction of Frictional Drag and Transmission Of Slack-Off Force In Horizontal Wells Using Neural Networks. SPE 51083, Kuwait University, 1998.

[31] L. Saputelli, H. Malki, J. Canelon, M. Nikolaou, A Critical Overview of Artificial Neural Network Applications in the Context of Continuous Oil Field Optimization. SPE Annual Technical Conference and Exhibition, 29 September-2 October, San Antonio, Texas, 2002.

[32] A. Shabalov, E. Semenkin, P. Galushin, Integration of Intelligent Information Technologies Ensembles for Modeling and Classification. Proceedings of the 7th International Conference on Hybrid Artificial Intelligent Systems - Volume Part I, 2012.

[33] D. Shahab Mohaghegh, Virtual-Intelligence Applications in Petroleum Engineering: Part 1Artificial Neural Networks. SPE 58046-JPT, 2000.

[34] Shahab D. Mohaghegh, Yasaman Khazaen, Application of Artificial Intelligence in the Upstream Oil and Gas Industry (pp.1-38). Nova Science Publishers, Inc., New York, 2011.

[35] S.R. Shadizadeh, F. Karimi, M. Zoveidavianpoor, Drilling Stuck Pipe Prediction in Iranian Oil Fields: An Artificial Neural Network Approach, Petroleum University of technology, Abadan, Iran, 2010 .

[36] E.M. Shokir, Artificial Intelligence: a new tool in oil and gas industry, 2001. 
[37] E.M Shokir, M.K. Emera, S.M. Eid, A.W. Wally, A New Optimization Model for 3d Well Design. Oil \& Gas Science and Technology Vol. 59, No. 3, pp. 255-266, 2004.

[38] S.V. Shokouhi, P. Skalle, A. Aamodt, F. Srmo, Integration of Real-Time Data and Past Experiences for Reducing Operational Problems, 2009.

[39] C. Si ruvuri, S. Nagarakanti, R. Samuel, Stuck Pipe Prediction and Avoidance: A Convolutional Neural Network Approach. IADC/ SPE 98378, 2006

[40] D. M. Tate, A.E. Smith, Unequal-Area Facility Layout by Genetic Search. IIE Transactions 27, 465-472, 1995.
[41] V. Vapnik, The Nature of Statistical Learning Theory. $2^{\text {nd }}$ Ed, New York, Springer p.1-314, 1995.

[42] Y. Wang, M. Duan, D. Wang, J. Liu, Y. Dong, A Model for Deepwater Floating Platform Selection Based on BP Artificial Neural Networks. International Society of Offshore and Polar Engineers, 2011

[43] V. Yamaliev, E. Imaeva, T. Salakhov, About the Deep Drilling Equipment Technical Condition Recognition Method, Ufa State Petroleum Technological University, 2009.

[44] http://www.aiai.ed.ac.uk/index.html

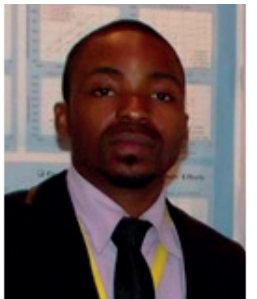

Opeyemi Bello is presently $\mathrm{PhD}$ candidate at the Sub-department for Drilling Engineering, Completion and Workover at the Institute of Petroleum Engineering (ITE), Clausthal University of technology, Germany. He's also a technical support engineer at ITE Engineering $\mathrm{GmbH}$. He holds an M.Sc in Petroleum Engineering with specialization in Drilling and Completion from the same University, and a B.Engr degree from Federal University of Technology, Akure Nigeria. His key qualifications and areas of interest include drilling rig optimization, testing of OCTG, drilling and production equipment, integrated computer aided analysis, software development, well integrity management, geothermal well and data mining.

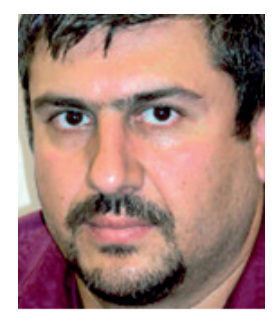

Catalin Teodoriu is Associate Professor at University of Oklahoma, Norman, Ok. Until 2015 he was head of the Sub-department for Drilling Technology, Completion and Workover at Clausthal University of Technology. Between 2006 and 2009, he was an assistant professor at Texas A\&M University, teaching courses on drilling topics such as Drilling Engineering, Introduction to Drilling Engineering, Completion and Workover, and Advanced Drilling Engineering. He now serves as an adjunct assistant professor in the Harold Vance Department of Petroleum Engineering at Texas A\&M University and as adjunct professor at the Oil and Gas University of Ploiesti in addition to his position at Oklahoma University. He holds a Ph.D. in technical sciences, with a specialty in oilfield equipment and an M.Sc. in mechanical engineering from the Oil and Gas University of Ploiesti and a Ph.D. in engineering from Clausthal University of Technology. Dr. Teodoriu is also an experienced instructor in drilling engineering, drilling facilities, casing and drill string mechanics, workover and drilling technologies topics. $\mathrm{He}$ is author of more than 150 publications from which more than 30 are peer-review, and 2 book chapters.

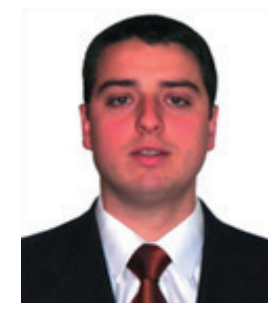

Dr. Javier Holzmann is Manager of the full Scale testing lab and Lecturer for topics related with OCTG technology since 2006 (Institute of Petroleum Engineering of TU Clausthal) and has worked as an R\&D Engineer for six years (2001-2006) in the R\&D Center of Tenaris-Siderca, Argentina. Dr. Holzmann has an equivalent M.Sc. degree (2001) from the Academy of Engineering, University of Buenos Aires, Argentina, and a PhD degree (2013) from the Technical University of Clausthal, Germany. Since 2001 Dr. Holzmann is involved in research activities related with OCTG design, testing and optimisation, makeup procedures, and development of laboratory testing devices and facilities. During this period he also performed witnessing and consulting activities related with OCTG qualification and running procedures.

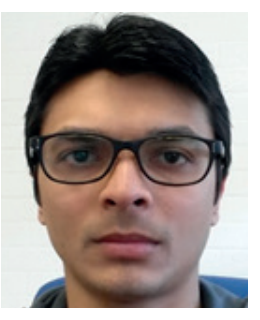

Tanveer Yaqoob is a research associate at the Sub-department for Drilling Engineering, Completion and Workover at the Institute of Petroleum Engineering (ITE), Technical University of Clausthal, Germany. He graduated as Bachelor (BE) in Petroleum Engineering (Specialization in Drilling \& Production) from NED University of Engineering and Technology, and completed Masters (MSc.) in Petroleum Engineering (Specialization in Drilling and Production) from Technical University of Clausthal. Tanveer has previous experience as a Trainee Drilling Engineer at MOL E\&P Intl. during his Bachelors and as a full-time technical consultant on Hydrocarbon separation and processing at SI Chemicals Pakistan after completion. Later, alongside his Masters at TU Clausthal, he gained practical experience on measurement \& collapse testing of OCTGs that led him to join ITE as research associate after his studies. Tanveer is 26 years of age and is now preparing his Doctor Thesis on OCTG Collapse behavior together with his occupation at ITE. 